\title{
SPATIAL AND TEMPORAL DISTRIBUTION OF THE CLOUD HEIGHT AND CLOUD THICKNESS OVER CHINA AND THE ADJACENT AREAS BASED ON CALIOP
}

\author{
Xiao Feng ${ }^{1,2, *}$, Hongke $\mathrm{Cai}^{2}$, Bowei Wang ${ }^{1}$, Xiaomin $\mathrm{Li}^{1}{ }^{1}$, Liang Zhang ${ }^{1}$ \\ ${ }^{1}$ Sichuan Meteorological Disaster Prevention Technology Center, Chengdu 610072, China - fty882@163.com, \\ Oliviawong6@163.com,1xm911020@163.com, stephenzl@foxmail.com \\ ${ }^{2}$ Plateau Atmospheric and Environment Laboratory of Sichuan Province, College of Atmospheric Science, Chengdu University of \\ Information Technology, Chengdu 610225, China -caihk@cuit.edu.cn
}

\section{Commission III, WG III/8}

KEY WORDS: CALIOP, Cloud Height, Cloud Thickness, Spatial Distribution, Seasonal Variation

Based on CALIOP data, spatial and temporal distribution of cloud height and thickness over China as well as the adjacent areas have been analysed in this paper. The results show significant regional differences. The heights of clouds that lie to the south of $27.6^{\circ} \mathrm{N}$ are greater than those to the north of $27.6^{\circ} \mathrm{N}$. The highest and thickest clouds are located above the Bay of Bengal and the Western Pacific, while the lowest values distribute in the northwest of the Tibetan Plateau and Sichuan Basin. The clouds ranging from $0.3 \mathrm{~km}$ to 0.6 $\mathrm{km}$ thickness account for a large proportion of total clouds. And the probability of occurrence of clouds decreases as cloud thickness increases. Overall, within the area under study, the thick clouds are higher than the thin clouds. Besides, low and thin clouds occur more frequently than high and thick clouds. As for their seasonal variation, the height of clouds peaks in summer. In addition, the mean of cloud thickness to the south of $27.6^{\circ} \mathrm{N}$ is $2.4 \mathrm{~km}$ thicker in summer than in any other season.

\section{INTRODUCTION}

The energy distribution of the earth-atmosphere system is regulated and influenced by cloud radiation. When covered by clouds, the earth's albedo is twice as high as that under clear-sky conditions (Ramanathan et al., 1989; Curry et al., 1996). This effect is closely related to the microphysical properties, macroscopic properties, and optical properties of the cloud (Charlson et al., 1987; Albrecht et al., 1988; Kiehl, 1994).In the analysis of cloud radiation characteristics, CVS (Cloud Vertical Structure) has been receiving much attention. Its essential components, namely, Cloud height (incl. Cloud Top Height, $\mathrm{CTH}$, and Cloud Base Height, $\mathrm{CBH}$ ) and thickness, are also significant for the study (Wang et al., 2000).

On the premise of considering the cloud as a uniform single layer, some studies have discussed the distribution characteristics of cloud amount and types, as well as their effects on the radiation balance of the earth-atmosphere system based on data detected via traditional methods. (Wang et al., 1998; Rossow et al., 1999; Chen et al., 2000; Warren et al., 2007).There are also preliminary studies that analyze the characteristics of the CVS distribution. (Wang et al., 2000; Mace et al., 2009; Bourgeois et al., 2016; Yan, 2016). However, studies have shown that multi-layer clouds $(\mathrm{N}>1)$ play a vital role in the radiation balance of the earth-atmosphere system when clouds overlap. (Stephens et al., 2004; Huang et al., 2006; Pan et al., 2015). Therefore, in order to obtain more accurate distribution characteristics of CVS, this paper analyses the distribution characteristics and variation laws of single-layer and multi-layer clouds at different heights in China and the adjacent areas during the past ten years by using satellite data, which may provide references for climate change research.

"Xiao Feng. fty882@163.com 


\section{DATA AND METHODS}

This paper selects China and the adjacent areas $\left(0^{\circ} \mathrm{N} \sim 55^{\circ} \mathrm{N}\right.$, $\left.70^{\circ} \mathrm{E} \sim 140^{\circ} \mathrm{E}\right)$ as research subjects, and divides the areas into $1.2^{\circ} \times 1.2^{\circ}$ latitude and longitude grids according to the coverage of CALIPSO (Cloud-Aerosol Lidar and Infrared Pathfinder Satellite Observations) orbits (Figure 1). Using the $1 \mathrm{~km}$ horizontal resolution cloud product of CALIPSO (CAL_LID_L2_01kmCLay-Standard-V4-10) from June 2006 to May 2016, the height and thickness distribution characteristics of different level in the areas under study were analysed.

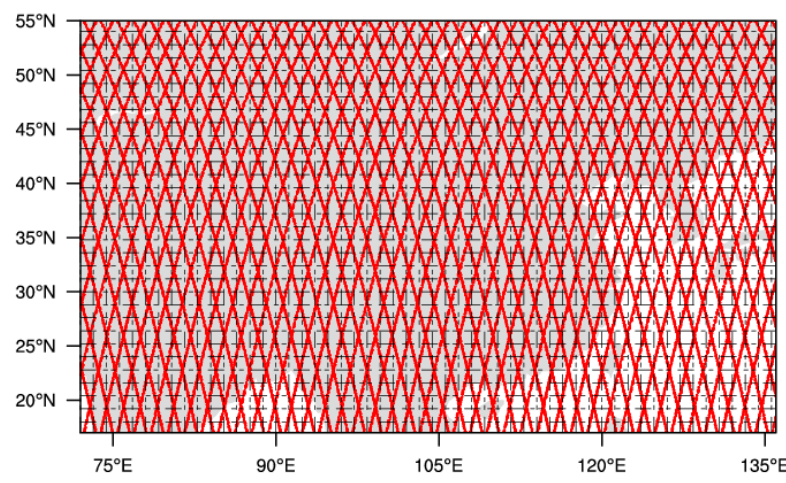

Figure 1. Track coverage of CLIPSO satellites over China and the adjacent areas within one year

In this study, the height of clouds is the relative height after subtracting the DEM_Surface_Elevation.

\section{RESULTS}

\subsection{Horizontal Distribution of Cloud Height and Cloud Thickness}

\subsubsection{Horizontal Distribution of CTH and CBH: There is} a significant regional difference between $\mathrm{CTH}$ and $\mathrm{CBH}$ in different level of clouds. Based on the detection method of CALIOP, the first layer contains the single layer clouds, the upper layer clouds of the double-layer clouds and the top layer clouds of the three-layer clouds.

With $27.6^{\circ} \mathrm{N}$ as the boundary, the $\mathrm{CTH}$ is over $9 \mathrm{~km}$ to the south of $27.6^{\circ} \mathrm{N}$. In the Bay of Bengal, the Indochina Peninsula and parts of the Malay Peninsula, the CTH of the first layer clouds can be as high as $14 \mathrm{~km} .27 .6^{\circ} \mathrm{N} \sim 36^{\circ} \mathrm{N}$, in Tibetan Plateau with an altitude over $3.1 \mathrm{~km}$, the $\mathrm{CTH}$ in the western part of the plateau is $3 \sim 4 \mathrm{~km}$, which is $1 \sim 2 \mathrm{~km}$ lower than the eastern part of the plateau.
At the same latitude, in the eastern part of China, in the eastern seas and in the Tarim Basin, the CTH of the first level clouds is $7 \sim 8 \mathrm{~km}$. To the north of $46.8^{\circ} \mathrm{N}$, the $\mathrm{CTH}$ of the Mongolian Plateau is about $6 \mathrm{~km}$ (Figure 2).

As shown in Figure $2 b$, the $\mathrm{CBH}$ distribution characteristics of the first layer of clouds are consistent with CTH. In the low latitude tropics to the south of $27.6^{\circ} \mathrm{N}, \mathrm{CBH}$ is more than $10 \mathrm{~km}$, except for the northern part of the Indian Ocean, and the Tibetan Plateau is less than $4 \mathrm{~km}$. The $\mathrm{CBH}$ in the Sichuan Basin and its surrounding areas are lower than that in the eastern part of China. The variation range of the Mongolian plateau CBH is $3 \sim 6 \mathrm{~km}$.
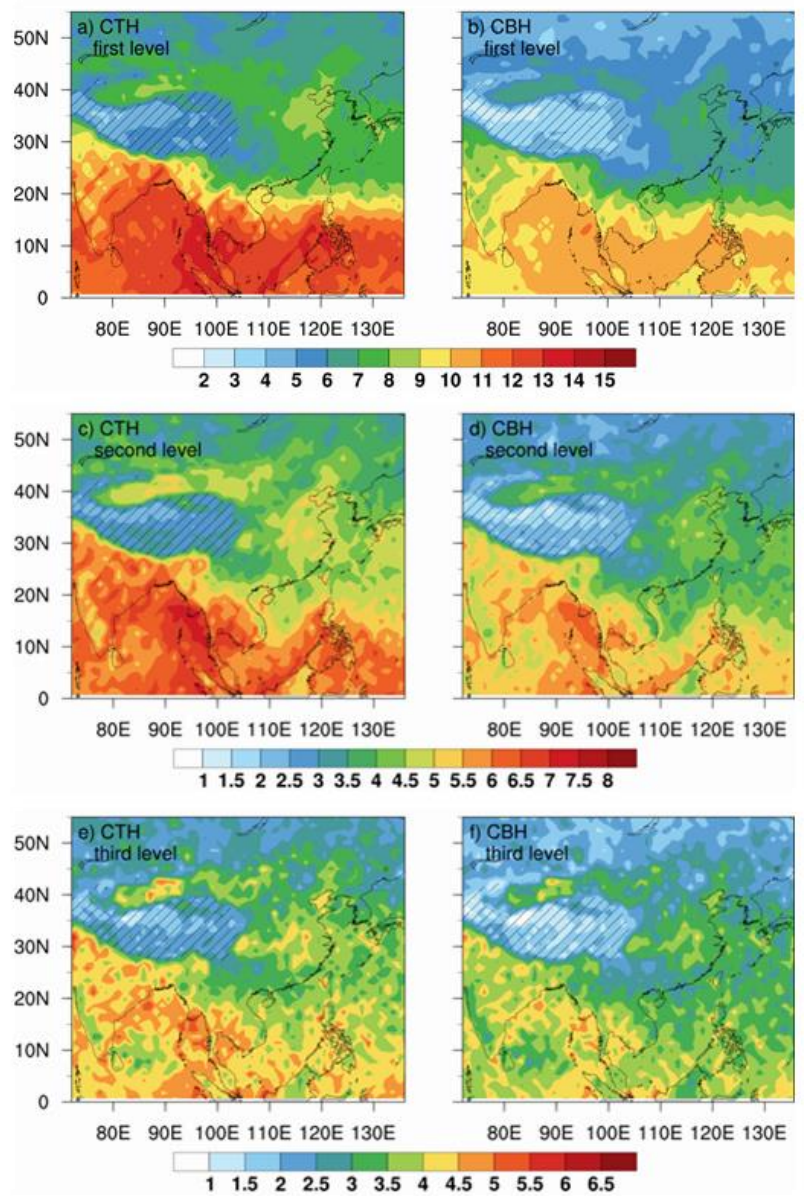

Figure 2. Horizontal distribution of CTH (a, c, e) and $\mathrm{CBH}(\mathrm{b}, \mathrm{d}, \mathrm{f})$ in different levels (first, second, third) of clouds.

The shaded part indicates that the surface elevation is above

$$
3.1 \mathrm{~km}(680 \mathrm{hPa})
$$

The second layer of clouds consist of multi-layered clouds, including the upper layer cloud of the double-layered cloud and 
the middle layer cloud of the three-layered cloud. The horizontal distribution of the $\mathrm{CTH}$ and the $\mathrm{CBH}$ is similar to that of the first layer cloud (see Figures 2c and 2d).Values of cloud height are large in the area south of $27.6^{\circ} \mathrm{N}$. The $\mathrm{CTH}$ and $\mathrm{CBH}$ in the eastern region are lower than that in the west. The $\mathrm{CTH}$ and $\mathrm{CBH}$ are $6 \sim 7.5 \mathrm{~km}$ and $5 \sim 6.5 \mathrm{~km}$ in the Indian Peninsula and the Bay of Bengal, respectively. At the same latitude, $\mathrm{CTH}$ and $\mathrm{CBH}$ in the South China Sea and the western North Pacific are $4.5 \sim 6.5 \mathrm{~km}$ and $4 \sim 6 \mathrm{~km}$, respectively. The Tibetan Plateau is still a low-value area of $\mathrm{CTH}$ and $\mathrm{CBH}$. The $\mathrm{CTH}$ in the southern part of the Tibetan Plateau is no more than $3.5 \mathrm{~km}$, and $\mathrm{CBH}$ of the corresponding area is no more than $2.5 \mathrm{~km}$. The CTH in Southwest China is $4.5 \mathrm{~km}$ and $\mathrm{CBH}$ is $3.5 \mathrm{~km}$. In other parts of central and eastern continents of China, CTH and CBH differ from the eastern sea by 0.5 to $1 \mathrm{~km}$. The $\mathrm{CTH}$ and $\mathrm{CBH}$ of the Mongolian Plateau are about $1.5 \mathrm{~km}$ lower than the Tarim Basin and part of the region to the east of the Tarim Basin.

Since the probability of occurrence of clouds with four or more layers is less than $1 \%$, the bottom layer of a three-layer cloud is the main component of the third layer of clouds. As shown in Fig. 2e, with a boundary of $106^{\circ} \mathrm{E}$, the $\mathrm{CTH}$ is above $4 \mathrm{~km}$ in the low-latitude region to the west of $106^{\circ} \mathrm{E}$, and in a few areas it can reach $6 \mathrm{~km} .27 .6^{\circ} \mathrm{N} 36^{\circ} \mathrm{N}$, the $\mathrm{CTH}$ of the Tibetan Plateau is nearly $2 \mathrm{~km}$ lower than the mainland China and the sea in the east. At the same time, there is a $1.5 \mathrm{~km}$ difference between the Tarim Basin and the Mongolian Plateau. In the southeastern part of the Bay of Bengal and near the Malay Peninsula, the third layer of clouds has the largest $\mathrm{CBH}$, and the Tibetan Plateau and the Mongolian Plateau have the smallest values. In the rest of the area under study, the $\mathrm{CBH}$ of the third layer of clouds varied from 2.5 to $4 \mathrm{~km}$ (Fig. 2f).

The cloud top pressure in the Tibetan Plateau and the Mongolian Plateau is less than $440 \mathrm{hPa}$, and the altitude is above $7 \mathrm{~km}$, both of which are dominated by single-layer high clouds (Cai et al., 2017). Therefore, in this study, the characteristics of the relative heights of the clouds are smaller than those of other regions.

\subsubsection{Horizontal Distribution of Cloud Thickness:}

Overall, the cloud thickness varies from $0.3 \mathrm{~km}$ to $3.6 \mathrm{~km}$, with the range of $1.5 \sim 1.8 \mathrm{~km}$ accounting for $37 \%$, which concentrates in the area north of $27.6^{\circ} \mathrm{N}$, especially the main body of the Tibetan Plateau, the Tarim Basin and the Mongolian Plateau. The clouds thickness in the western part of the Tibet Plateau, the Sichuan Basin and the East China Sea is 1.2 to $1.5 \mathrm{~km}$, and the PDF (Probability Density Function) is $21 \%$. The thickness of the clouds between 2.1 and $2.4 \mathrm{~km}$ accounts for $12 \%$, mainly in the low-latitude region to the south of $27.6^{\circ} \mathrm{N}$.

In order to further analyse the regional characteristics of cloud height and thickness over China and the adjacent areas, this paper divides the research areas into six sub-regions according to the characteristics of $\mathrm{CTH}$ and $\mathrm{CBH}$ distribution in different regions. As shown in Figure 4 , they areArea $1\left(0^{\circ} \mathrm{N} \sim 27.6^{\circ} \mathrm{N}\right.$, $\left.70^{\circ} \mathrm{E} \sim 140^{\circ} \mathrm{E}\right), \operatorname{Area} 2\left(27.6^{\circ} \mathrm{N} \sim 36^{\circ} \mathrm{N}, 70^{\circ} \mathrm{E} \sim 108^{\circ} \mathrm{E}\right)$, Area3 $\left(36^{\circ} \mathrm{N} \sim 4\right.$ $\left.6.8^{\circ} \mathrm{N}, 70^{\circ} \mathrm{E} \sim 140^{\circ} \mathrm{E}\right), \operatorname{Area} 4\left(27.6^{\circ} \mathrm{N} \sim 46.8^{\circ} \mathrm{N}, 106.8^{\circ} \mathrm{E} \sim 122.4^{\circ} \mathrm{E}\right)$, $\operatorname{Area} 5\left(27.6^{\circ} \mathrm{N} \sim 46.8^{\circ} \mathrm{N}, 122.4^{\circ} \mathrm{E} \sim 140^{\circ} \mathrm{E}\right)$, Area6 $\left(46.8^{\circ} \mathrm{N} \sim 55^{\circ} \mathrm{N}\right.$, $\left.70^{\circ} \mathrm{E} \sim 140^{\circ} \mathrm{E}\right)$.
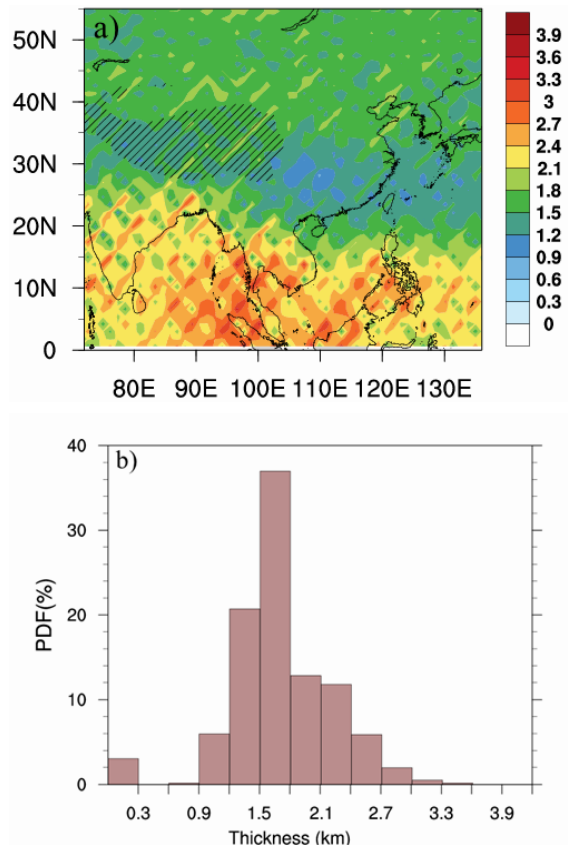

Figure 3. Horizontal distribution (a) and PDF (b) of the cloud thickness over China and the adjacent areas. The shaded part indicates that the surface elevation is above $3.1 \mathrm{~km}(680 \mathrm{hPa})$ 


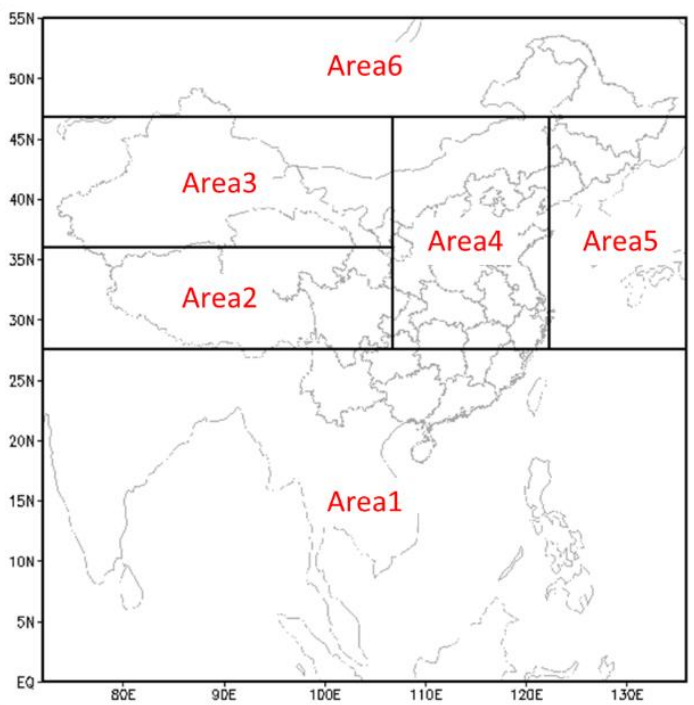

Figure 4. Six sub-areas of China and the adjacent areas.

According to the horizontal distribution of the cloud thickness in the area under study, the cloud thickness of $0.3 \sim 0.6 \mathrm{~km}$ has the highest probability of occurrence in the six regions, with more than 25\%, except for Area1 and Area6, and even more than $30 \%$ in Area2 and Area5. In Area1, Area5, and especially Area6, the cloud with a thickness below $0.3 \mathrm{~km}$ is a little more than the cloud with a thickness of $0.6 \sim 0.9 \mathrm{~km}$. At the same time, the cloud with thickness of $0.6 \sim 0.9 \mathrm{~km}$ in Area2 and Area3 contributes more to the total sample size of each region than cloud with thickness below $0.3 \mathrm{~km}$. As for the cloud with thickness above $0.6 \mathrm{~km}$, the probability of occurrence decreases as thickness increases. Except for Area1, the probability of cloud thickness of $3.3 \sim 3.6 \mathrm{~km}$ is less than $1 \%$ in other areas (Figure 5).
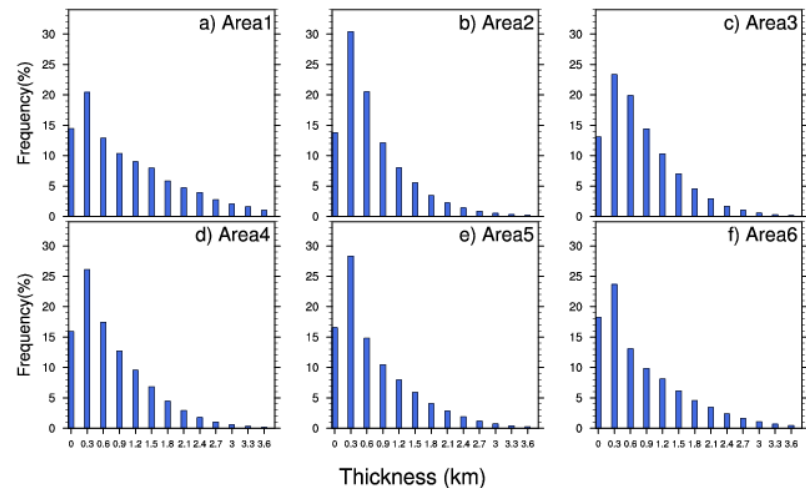

Figure 5. The probability of occurrence of clouds of different thicknesses in sub-regions (Area1, Area2, Area3, Area4, Area5, Area6) of China and the adjacent areas, $\%$.

\subsubsection{Relationship between Cloud Height and Cloud}

Thickness: By calculating the joint probability density of cloud height and thickness, their corresponding relationship in different regions is discussed (Fig. 6). Within the areas under study, the thick clouds are higher than the thin clouds, and low and thin clouds occur more frequently than high and thick clouds.

In Area1, the CTH with a high probability density is no more than $3 \mathrm{~km}$ and the thickness is less than $1.5 \mathrm{~km}$. High and thick clouds have a maximum probability density of $5 \%$. There are about $4 \%$ of the CTH in the $13 \sim 16 \mathrm{~km}$ and the thickness is $4 \mathrm{~km}$. There are also some clouds in between, with a probability of around 5\%. The clouds in Area2 are relatively higher and the thickness also increases, but the highest CTH does not exceed $12 \mathrm{~km}$. In Area 3, the CTH with a high probability density is 2 to $4 \mathrm{~km}$, and the clouds are very thin. As for Area 4, the height and thickness of the clouds below $8 \mathrm{~km}$ vary uniformly. Compared with Area1, the clouds of Area5 are lower and thinner. The low and thin clouds in $1 \sim 3 \mathrm{~km}$ have a higher probability of occurrence in Area5. This may be due to the stronger deep convection development in the Indian region than in eastern China.(Luo et al., 2009). For another, the clouds of Area6 are not much different from Area2. But, it is lower and thinner than the low clouds of Area1, and the high clouds are taller and thicker. This may be due to the relatively abundant water vapor and more convective activities in the Tibetan Plateau. Meanwhile, the troposphere of the Mongolian plateau has a high stability, which is not conducive to ascending motion and is prone to low clouds (Wang et al., 2011).

The distribution characteristics of $\mathrm{CTH}$ and $\mathrm{CBH}$ in each layer in China and the adjacent areas are as follows: the top layer of three-layer clouds is the highest; the top layer of double-layer clouds is the second; and the bottom layer of double-layer clouds and three-layer clouds is the lowest. At the same time, there are obvious regional differences in the height of single-layer clouds and three-layer clouds. In Area1 and Area3, the single-layer clouds are higher than the mid-layer of three-layer clouds, which are opposite to Area2, Area5, and Area6. In Area4, though the CTH of single-layer clouds is higher than the three-layer clouds, the $\mathrm{CBH}$ is similar. Meanwhile, the single-layer clouds are the thickest, and the bottom layer of three-layer clouds is the thinnest. 

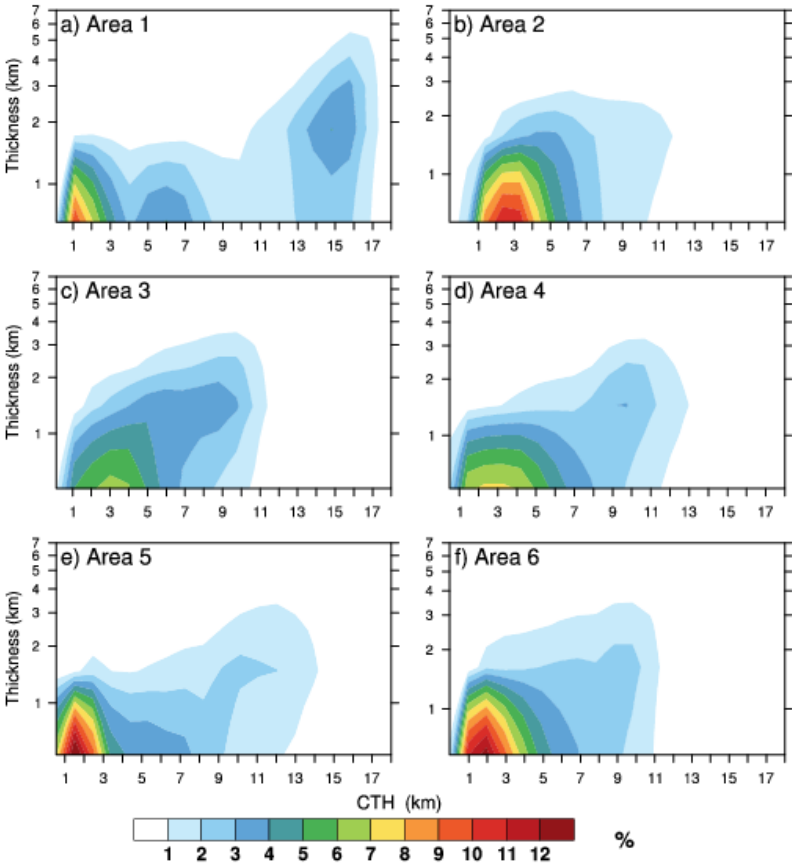

Figure 6. Joint probability density distribution of cloud thickness and $\mathrm{CTH}$ in sub-regions of China and the adjacent areas.

In summary, the cloud of Area1 is higher than other areas, and Area5 comes second, while Area6 is the lowest. The clouds develop higher in the low-latitude Area1 than mid-latitude Area5, and the clouds in the high-latitude plateau Area6 are lower than in the mid-latitude Area2. The single-layer clouds in each region are lower, but thicker, than the upper clouds of the three-layer and double-layer clouds.

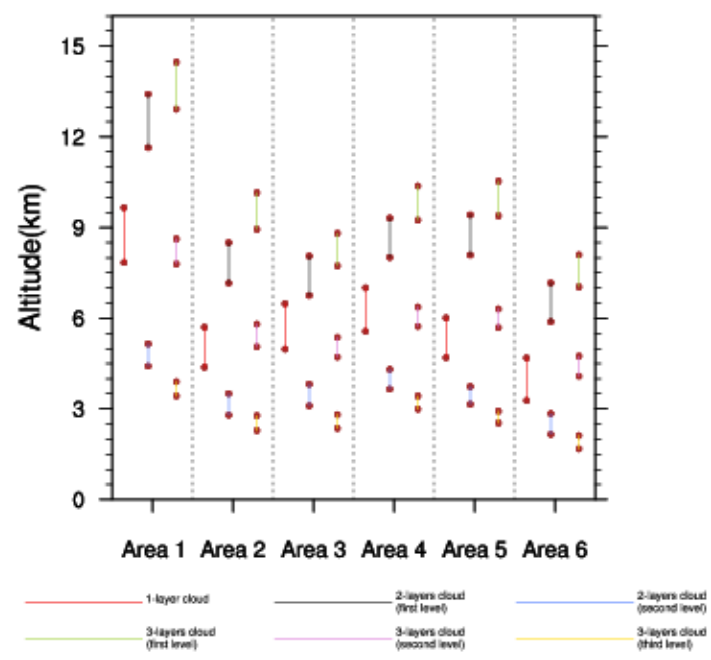

Figure 7. The height of different levels (first, second, third) clouds in sub-regions over China and the adjacent areas, $\mathrm{km}$.

\subsection{Seasonal Variations in Cloud Height and Cloud Thickness}

3.2.1 Seasonal Variations in CTH and CBH: The distribution characteristics of $\mathrm{CTH}$ and $\mathrm{CBH}$ in different layers are basically the same as their horizontal distribution, but the seasonal variations are obvious (Figure 8 and Figure 9). Summer has the highest cloud height, followed by spring, autumn and winter. In summer, the CTH of the uppermost clouds in the area south of the Tibetan Plateau is above $11 \mathrm{~km}$, and the $\mathrm{CBH}$ is no less than $9 \mathrm{~km}$. The $\mathrm{CTH}$ and $\mathrm{CBH}$ in the eastern coastal areas of China are $8 \sim 10 \mathrm{~km}$ and $6 \sim 9 \mathrm{~km}$, respectively. In the majority of other regions, $\mathrm{CTH}$ also exceeds $6 \mathrm{~km}$ and $\mathrm{CBH}$ exceeds $5 \mathrm{~km}$. The $\mathrm{CTH}$ and $\mathrm{CBH}$ of the uppermost cloud of the Tibetan Plateau are $3 \sim 6 \mathrm{~km}$ and $3 \sim 5 \mathrm{~km}$. In spring, the CTH of the first layer of clouds in the east of the Tarim Basin increases, while CTH of the remaining areas decreases by 1 to $2 \mathrm{~km}$. The $\mathrm{CBH}$ changes are small. In autumn and winter, the $\mathrm{CTH}$ of the first layer of clouds does not change much in the Tibetan Plateau. In winter, the $\mathrm{CBH}$ of the Mongolian Plateau reduces by about $1 \mathrm{~km}$, and the $\mathrm{CTH}$ and $\mathrm{CBH}$ of the first level clouds in the eastern China decrease to $5 \mathrm{~km}$ and $4 \mathrm{~km}$, respectively.

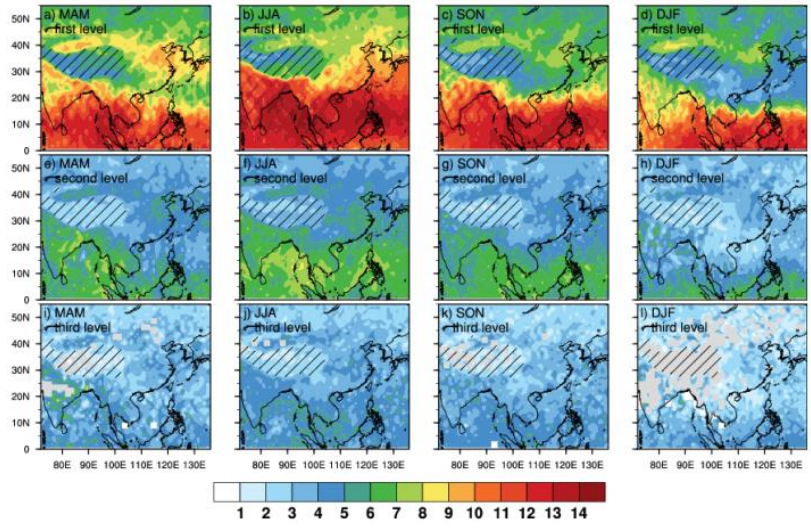

Figure 8. Distribution of CTH in different levels (first, second, third) over China and the adjacent areas in different seasons

(MAM, JJA, SON, and DJF), km. The shaded part indicates that the surface elevation is above $3.1 \mathrm{~km}(680 \mathrm{hPa})$ 

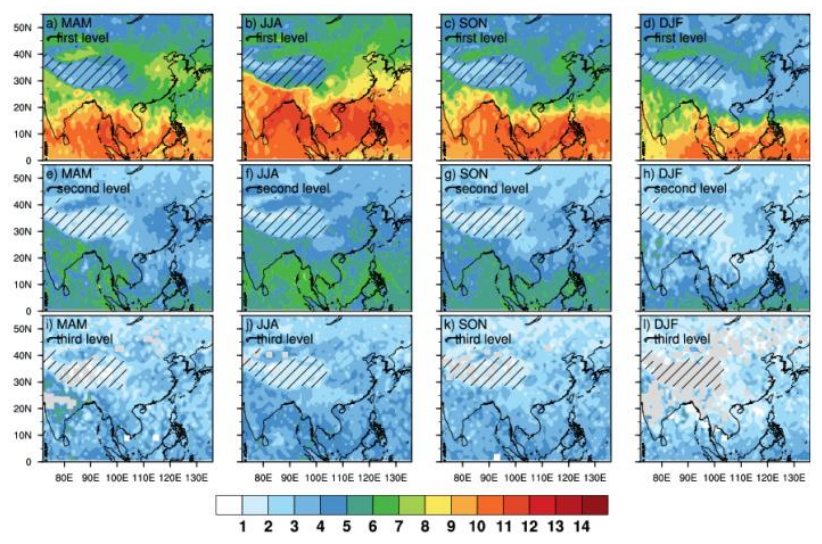

Figure 9. Seasonal Distribution of CBH in each level (first, second, third) over China and the adjacent areas in different seasons (MAM, JJA, SON, and DJF), km. The shaded part indicates that the surface elevation is above $3.1 \mathrm{~km}(680 \mathrm{hPa})$

\subsubsection{Seasonal Variation of Cloud Thickness: As shown} in Fig. 10, the seasonal variation of cloud thickness is very prominent. In the low-latitude region to the south of $27.6^{\circ} \mathrm{N}$, the clouds are the thickest in summer, exceeding $2.4 \mathrm{~km}$. In fall, the cloud thickness in the northern part of the Bay of Bengal and the Indian Peninsula decreases slightly. In winter, only in the tropics of $0^{\circ} \mathrm{N} \sim 10^{\circ} \mathrm{N}$, the cloud thickness is above $2.4 \mathrm{~km}$. The clouds in southern Tibetan Plateau during summer and those in northern Tibetan Plateau during spring are the thickest. The thinnest clouds can be found in the eastern and central parts of mainland China and the eastern sea. On the contrary, the cloud thickness in spring and winter in the east of Tarim Basin and Mongolian Plateau area exceeds $1.6 \mathrm{~km}$, and even $2.4 \mathrm{~km}$ in some areas, and decreases in autumn. The thinnest cloud occurs in summer, mainly varying from $1.2 \mathrm{~km}$ to $1.6 \mathrm{~km}$.

\subsubsection{Seasonal Variation in the Relationship between}

Cloud Height and Cloud Thickness: In the area under study, the relationship between cloud height and thickness of single-layer clouds and multi-layer clouds in different regions and seasons is shown as follows (see Figure 11). In general, the seasonal variations of CTH and CBH in different levels in each region are basically the highest in summer and the lowest in winter. In winter, the cloud height of Area2 is significantly higher than that of the other three seasons. It is worth mentioning that, the $\mathrm{CTH}$ and $\mathrm{CBH}$ of single-layer clouds, and CTH of double-layer clouds, are higher in spring than in summer. In Area4, the CTH of the third layer of three-layer clouds is higher in winter than in summer.

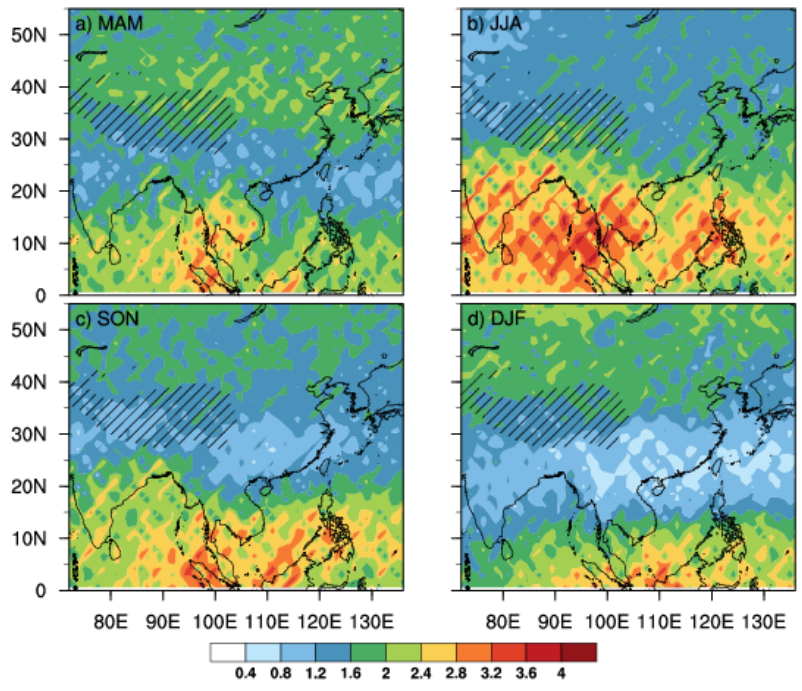

Figure 10. Distribution of cloud thickness in different seasons

(MAM, JJA, SON, and DJF), km. The shaded part indicates that the surface elevation is above $3.1 \mathrm{~km}(680 \mathrm{hPa})$

In summer, the single-layer cloud is the highest in Area1, with $\mathrm{CTH}$ and $\mathrm{CBH}$ of $11.5 \mathrm{~km}$ and $9 \mathrm{~km}$, respectively, and the lowest in Area6. The heights of single-layer clouds in Area4, Area5, Area2, and Area3 sequentially reduce. In winter, Area5 is the lowest and Area1 is the highest, but Area6 has the thickest single-layer clouds.

For double-layer clouds, the first layer is still the highest in Area1 during summer, with CTH exceeding $14 \mathrm{~km}$ and $\mathrm{CBH}$ of $12 \mathrm{~km}$. In Area3 and Area4, CTH is $8 \mathrm{~km}$ and $7.7 \mathrm{~km}$, respectively. Cloud heights in other regions are within these values, and are the lowest in Area2 during winter, with $\mathrm{CTH}$ of $6.5 \mathrm{~km}$ and $\mathrm{CBH}$ of $5.5 \mathrm{~km}$, respectively. For the first level of three-layer clouds, the cloud height in Area1 exceeds $12 \mathrm{~km}$ in summer, and $\mathrm{CTH}$ is $12 \mathrm{~km}$ and $\mathrm{CBH}$ is $11.5 \mathrm{~km}$ in winter. In Area2, the cloud height is significantly lower in winter than in other seasons, as CTH is only $5 \mathrm{~km}$ and $\mathrm{CBH}$ is $4.5 \mathrm{~km}$ in winter. The mid-level of three-layer clouds, the second level of double-layer clouds, and the third level of three-layer clouds successively decrease in each season. In addition to single-layer clouds, cloud thickness of each region also decreases slightly as cloud height decreases in different seasons. 

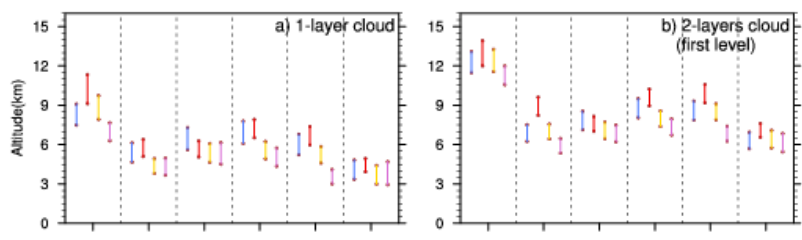

Area 1 Area 2 Area 3 Area 4 Area 5 Area 6

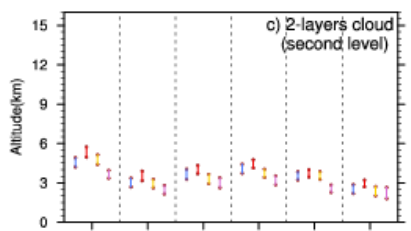

Area 1 Area 2 Area 3 Area 4 Area 5 Area 6

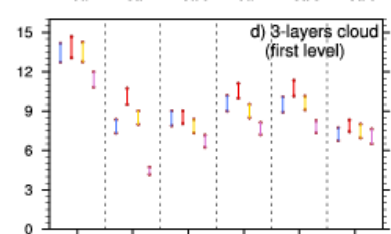

Area 1 Area 2 Area 3 Area 4 Area 5 Area

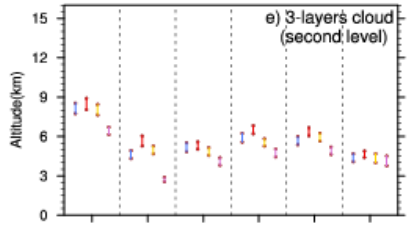

Area 1 Area 2 Area 3 Area 4 Area 5 Area 8

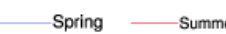

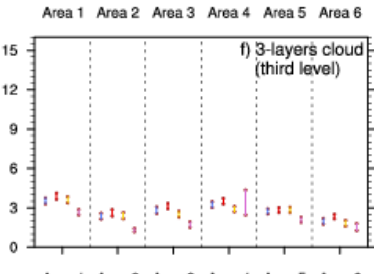

Area 1 Area 2 Area 3 Area 4 Area 5 Area 6

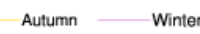

Figure 11. The height of different levels (the first, second and third) clouds in different seasons (MAM, JJA, SON, and DJF) in sub-regions over China and the adjacent areas, $\mathrm{km}$.

\section{CONCLUSIONS}

Based on CALIOP data, spatial and temporal distribution of cloud height and thickness over China as well as the adjacent areas have been analysed in this paper. According to the characteristics of $\mathrm{CTH}$ and $\mathrm{CBH}$ distribution in different regions, the research scope has been divided into six sub-regions. By discussing the horizontal distribution and seasonal variations of cloud height and cloud thickness in different regions, we have a more detailed understanding of CSV in China and the adjacent areas. The analysis results are as follows:

(1) There is a clear regional difference between CTH and CBH in different levels of clouds. The heights of clouds that lie to the south of $27.6^{\circ} \mathrm{N}$ are greater than those to the north of $27.6^{\circ} \mathrm{N}$. The highest and thickest clouds are located on the Bay of Bengal and the Western Pacific, as the CTH and $\mathrm{CBH}$ of the first layer clouds can be as high as $14 \mathrm{~km}$ and $11 \mathrm{~km}$, respectively. The CTH in the western part of the Tibetan Plateau is $3 \sim 4 \mathrm{~km}$, while the $\mathrm{CBH}$ is less than $3 \mathrm{~km}$. Values of cloud heights in the southwest region, the southeast part of China's mainland, and over the eastern seas are similar to that in the Tarim Basin, but all in the middle of high and low limits. The cloud height in the Mongolian Plateau is lower than that in the Tarim Basin and its eastern regions. Compared with the first level clouds, the second level clouds and the third level clouds have the same distribution characteristics, but the height changes prominently.

(2) Overall, the cloud thickness varies from $0.3 \mathrm{~km}$ to $3.6 \mathrm{~km}$. Among them, the range of $1.5 \sim 1.8 \mathrm{~km}$ accounts for $37 \%$ of the total. The thickness of the clouds in the western part of the Tibet Plateau, the Sichuan Basin and the East China Sea is 1.2 to 1.5 $\mathrm{km}$, and the PDF is $21 \%$. The thickness of the clouds between 2.1 and $2.4 \mathrm{~km}$ accounts for $12 \%$, mainly in the low-latitude area to the south of $27.6^{\circ} \mathrm{N}$

(3) The distribution characteristics of $\mathrm{CTH}$ and $\mathrm{CBH}$ in different layers are basically the same as their horizontal distribution, but the seasonal variations are obvious. Summer has the highest cloud height, followed by spring, autumn and winter. The seasonal variation of cloud thickness is very prominent. The clouds in the east of the Tarim Basin and the Mongolian Plateau are thicker in spring and winter, and the thinnest in summer.In addition, the cloud thickness in area to the south of $27.6^{\circ} \mathrm{N}$ is more than $2.4 \mathrm{~km}$ in summer.

(4) The cloud in Area1 is highest overall, followed by Area5, and Area6 is the lowest. The clouds develop higher in the low-latitude Area1 than mid-latitude Area5, and the clouds in the high-latitude plateau Area6 are lower than in the mid-latitude Area2. Overall, the seasonal variations of CTH and $\mathrm{CBH}$ in different levels in each region are basically the highest in summer and the lowest in winter. Overall, within the area understudy, the thick clouds are higher than the thin clouds, and low and thin clouds occur more frequently than high and thick clouds. Nevertheless, single-layer clouds are both lower and thicker than the first layer of three-layer clouds and the upper layer of double-layer clouds.

\section{ACKNOWLEDGEMENTS}

This work was supported by Sichuan Science and Technology Program 2019YJ0621, National Key R\&D Program of China 2018YFC1505702. All figures were created using the NCAR Command Language (NCL) (2016) (http:// www.ncl.ucar.edu). The CALIOP products were downloaded from the Atmospheric Science Data Center (https://earthdata.nasa.gov) 


\section{REFERENCES}

Albrecht, B.A., Randall, D. A., Nicholls, S., 1988. Observations of marine stratocumulus clouds during fire. Bulletin of the American Meteorological Society, 69(6): 618-626.

Bourgeois, Q., Ekman, A.M.L., Igel, M.R., et al., 2016. Ubiquity and impact of thin mid-level clouds in the tropics. Nature Communications, 7: 12432. doi:10.1038/ncomms 12432.

Cai, H., Feng, X., Chen, Q., et al., 2017. Spatial and temporal features of the frequency of cloud occurrence over China based on CALIOP. Advances in Meteorology, 2017: 1-11.

Charlson, R.J., Warren, S.G., Lovelock, J.E., et al., 1987. Oceanic phytoplankton, atmospheric sulphur, cloud albedo and climate. Nature, 326(6114): 655-661. doi:10.1038/326655a0.

Chen, T., Zhang, Y., Rossow, W.B., 2000. Sensitivity of atmospheric radiative heating rate profiles to variations of cloud layer overlap. Journal of climate, 13(16): 2941 - 2959.

Curry, J.A., Rossow, W.B., Randall, D., et al., 1996. Overview of Arctic cloud and radiation characteristics. Journal of Climate, 8(9): 1731-1764.

Huang, J., Minnis, P., Lin, B., et al., 2006. Determination of ice water path in ice - over - water cloud systems using combined MODIS and AMSR - E measurements. Geophysical Research Letters, 33(21). doi:10.1029/2006GL027038.

Kiehl, J.T., 1994. Sensitivity of a GCM climate simulation to differences in continental versus maritime cloud drop size. Journal of Geophysical Research: Atmospheres, 99(D11): 23,107-23,115. doi:10.1029/94JD01117.

Yan, Y., Liu, Y., Lu, J., 2016. Cloud vertical structure, precipitation, and cloud radiative effects over Tibetan Plateau and its neighboring regions. Journal of Geophysical Research Atmospheres, 10(121): 5864-5877.

Luo, Y., Zhang, R., Wang, H., 2009. Comparing occurrences and vertical structures of hydrometeors between eastern China and the Indian monsoon region using CloudSat/CALIPSO Data. Journal of Climate, 22(4): 1052-1064.
Mace, G.G., Zhang, Q., Vaughan, M., et al., 2009. A description of hydrometeor layer occurrence statistics derived from the first year of merged Cloudsat and CALIPSO data. Journal of Geophysical Research, 114(8): D00A26.

Pan, Z., Gong, W, Mao, F., et al., 2015. Macrophysical and optical properties of clouds over east Asia measured by CALIPSO. Journal of Geophysical Research Atmospheres, 120(22): 11,653 - 11,668. doi:10.1002/2015JD023735.

Ramanathan, V., Cess, R.D., Harrison, E.F., et al., 1989. Cloud-radiative forcing and climate: results from the earth radiation budget experiment. Science, 243(4887): 57-63.

Rossow, W.B., Schiffer, R.A., 1999. Advances in understanding clouds from ISCCP. Bulletin of the American Meteorological Society, 80(11): 2261-2288.

Stephens, G.L., Wood, N.B., Gabriel, P.M., 2004. An assessment of the parameterization of subgrid-scale cloud effects on radiative transfer. Part I : Vertical overlap. Journal of Atmospheric Sciences, 61(6): 715-732.

Wang, H., Luo, Y., Zhang. R., 2011. Analyzing seasonal variation of clouds over the Asian monsoon regins and the Tibetan Plateau regin using CloudSat/CALIPSO. Chinese Journal of Atmospheric Science, 35(6): 1117-1131.

Wang, J., Rossow, W.B., Zhang, Y., 2000. Cloud vertical structure and its variations from a 20-Yr global rawinsonde dataset. Journal of Climate, 13(17): 3041 - 3056.

Wang, J., Rossow, W.B., 1998. Effects of Cloud vertical structure on atmospheric circulation in the GISS GCM. Journal of Climate, 11(11): 3010-3029.

Warren, S.G., Eastman, R.M., Hahn, C.J., 2007. A survey of changes in cloud cover and cloud types over land from surface observations, 1971 - 96. Journal of Climate, 20(4): 717-738. 